\title{
Characterization of anthropogenic methane plumes with the Hyperspectral Thermal Emission Spectrometer (HyTES): a retrieval method and error analysis
}

\author{
Le Kuai ${ }^{1}$, John R. Worden ${ }^{2}$, King-Fai Li ${ }^{3}$, Glynn C. Hulley ${ }^{2}$, Francesca M. Hopkins ${ }^{2}$, Charles E. Miller ${ }^{2}$, \\ Simon J. Hook ${ }^{2}$, Riley M. Duren ${ }^{2}$, and Andrew D. Aubrey ${ }^{2}$ \\ ${ }^{1}$ Joint Institute for Regional Earth System Science \& Engineering, University of California, Los Angeles, USA \\ ${ }^{2}$ Jet Propulsion Laboratory, California Institute of Technology, Pasadena, California, USA \\ ${ }^{3}$ Department of Applied Mathematics, University of Washington, Seattle, Washington, USA
}

Correspondence to: L. Kuai (lkuai@g.ucla.edu)

Received: 21 December 2015 - Published in Atmos. Meas. Tech. Discuss.: 27 January 2016

Revised: 14 June 2016 - Accepted: 21 June 2016 - Published: 21 July 2016

\begin{abstract}
We introduce a retrieval algorithm to estimate lower tropospheric methane $\left(\mathrm{CH}_{4}\right)$ concentrations from the surface to $1 \mathrm{~km}$ with uncertainty estimates using Hyperspectral Thermal Emission Spectrometer (HyTES) airborne radiance measurements. After resampling, retrievals have a spatial resolution of $6 \times 6 \mathrm{~m}^{2}$. The total error from a single retrieval is approximately $20 \%$, with the uncertainties determined primarily by noise and spectral interferences from air temperature, surface emissivity, and atmospheric water vapor. We demonstrate retrievals for a HyTES flight line over storage tanks near Kern River Oil Field (KROF), Kern County, California, and find an extended plume structure in the set of observations with elevated methane concentrations ( $3.0 \pm 0.6$ to $6.0 \pm 1.2 \mathrm{ppm}$ ), well above mean concentrations $(1.8 \pm 0.4 \mathrm{ppm})$ observed for this scene. With typically a $20 \%$ estimated uncertainty, plume enhancements with more than $1 \mathrm{ppm}$ are distinguishable from the background values with its uncertainty. HyTES retrievals are consistent with simultaneous airborne and ground-based in situ $\mathrm{CH}_{4}$ mole fraction measurements within the reported accuracy of approximately $0.2 \mathrm{ppm}$ (or $\sim 8 \%$ ), due to retrieval interferences related to air temperature, emissivity, and $\mathrm{H}_{2} \mathrm{O}$.
\end{abstract}

\section{Introduction}

Methane $\left(\mathrm{CH}_{4}\right)$ is an important greenhouse gas. Although the atmospheric concentration of $\mathrm{CH}_{4}$ is substantially lower than that of $\mathrm{CO}_{2}$, the radiative forcing per $\mathrm{CH}_{4}$ molecule is approximately 20 times greater than that of $\mathrm{CO}_{2}$ (Ramaswamy, 2001; Solomon et al., 2007). Global concentrations of $\mathrm{CH}_{4}$ have increased nearly threefold from $\sim 700 \mathrm{ppb}$ since the preindustrial Holocene (1000 to $1800 \mathrm{AD}$ ) to $\sim 1850 \mathrm{ppb}$ today (Etheridge et al., 1998; NOAA, 2013). Approximately 60-70\% of modern $\mathrm{CH}_{4}$ emissions originate from anthropogenic sources (Lelieveld et al., 1998).

Major anthropogenic sources of $\mathrm{CH}_{4}$ include energy, industrial, agricultural, and waste management sectors (Kirschke et al., 2013). Hence $\mathrm{CH}_{4}$ levels are often higher than the global mean near areas such as oil fields, coal mines, natural gas systems, and feedlots. Quantifying and reducing uncertainties associated with anthropogenic $\mathrm{CH}_{4}$ emissions generally depend on the capability to monitor and quantify these super-emitters or sources of leaking (e.g., Caulton et al., 2014 and refs therein). For example, the considerable contributions of a few sources of leaking is one hypothesis for explaining inconsistencies between top-down and bottom-up estimates of the $\mathrm{CH}_{4}$ emission inventories for large cities or gas exploration regions (Wunch et al., 2009; Hsu et al., 2010; Frankenberg et al., 2011; Wennberg et al., 2012; Peischl et al., 2013; Jeong et al., 2013; Kort et al., 2014; Schneising et al., 2014; Wong et al., 2015; McKain et al., 2015). 
Spaceborne measurements cannot resolve these point sources because the satellite footprints are usually much larger than the spatial scale of such sources. This study describes a quantitative, robust and reliable retrieval algorithm for estimating $\mathrm{CH}_{4}$ concentrations in anthropogenic $\mathrm{CH}_{4}$ plumes at the $10-100 \mathrm{~m}$ scale using airborne radiance measurements from the airborne Hyperspectral Thermal Emission Spectrometer (HyTES) (Hook et al., 2013, 2016). HyTES is a pushbroom imaging spectrometer that produces a wide swath $(\sim 1 \mathrm{~km}$ for $1 \mathrm{~km}$ flight altitude) thermal infrared (TIR) image with high spectral and spatial resolution that incorporates a number of key state-of-the-art technologies developed at JPL. The instrument utilizes 256 spectral channels between 7.5-12 $\mu \mathrm{m}$ and 512 spatial pixels cross track with $\sim 2 \mathrm{~m}$ spatial resolution of when observing from low altitude of about $\sim 1000 \mathrm{~m}$ above ground level (a.g.l.). Previous studies produced maps of $\mathrm{CH}_{4}$ distributions from airborne hyperspectral TIR sensor radiances using methods such as cluster-tuned matched filter detection (CMF) (Funk, 2001). Such correlative approaches are quite useful to quickly identify point sources; however, they do not yield quantitative estimates of the $\mathrm{CH}_{4}$ plume concentrations or the corresponding $\mathrm{CH}_{4}$ emission rates. Some recent work by Krings et al. (2013), Tratt et al. (2014), and Gerilowski et al. (2015) demonstrates the quantification of $\mathrm{CH}_{4}$ emission rates using different airborne remote sensing data but none of them could provide high spatial resolution images of a plume with actual $\mathrm{CH}_{4}$ concentrations and background estimates. Our approach to estimate $\mathrm{CH}_{4}$ concentrations using HyTES thermal IR radiance measurements is based on the $\mathrm{CH}_{4}$ optimal estimation atmospheric retrieval algorithm developed for the Aura Tropospheric Emission Spectrometer (TES) (Worden et al., 2004, 2012; Bowman et al., 2006). This retrieval method not only estimates the $\mathrm{CH}_{4}$ concentrations but also quantifies the corresponding uncertainties and vertical sensitivity of the estimate using a Bayesian approach.

HyTES has collected imagery data during flights over the extent of the Kern River Oil Field (KROF), Kern County, California, on three different occasions during February 2015. This paper focuses on describing a retrieval algorithm to quantify $\mathrm{CH}_{4}$ concentrations and corresponding error analysis based on these HyTES TIR radiances (Sects. 2 and 3). Due to the highly variation of the plume and its dependence on wind conditions, the best image of a large-scale and well-developed $\mathrm{CH}_{4}$ plume is recorded on 5 February. We choose to show the retrieval results for this flight line to demonstrate the quality of HyTES $\mathrm{CH}_{4}$ data (Sect. 4). In Sect. 5, the retrieval estimated background and plume values are cross-compared with nearby in situ measurements from airborne and on-road sensors. The conclusions are summarized in Sect. 6. The analysis of more retrieval results for other flight lines will be discussed in future papers.

\section{Retrieval strategy}

We estimate $\mathrm{CH}_{4}$ mixing ratios by applying the retrieval algorithm originally designed to quantify trace gases from radiances measured by the TES on board the Earth Observing System's Aura Satellite. The primary modifications of the TES forward model to simulate measured radiances by the airborne HyTES are to correct the optical path since the observational instrument is now located $\sim 1 \mathrm{~km}$ above the ground instead of above the top of the atmosphere, and also to account for the different instrument line shape used to convolve the modeled radiances to the observed radiances.

\section{$2.1 \mathrm{HyTES} \mathrm{CH}_{4}$ spectral windows}

We use radiances from 7.5 to $9.2 \mu \mathrm{m}$ (or 1092.3 to $1329.8 \mathrm{~cm}^{-1}$ ), which includes the $\mathrm{CH}_{4}$ band at approximately $8.5 \mu \mathrm{m}$ to estimate $\mathrm{CH}_{4}$ concentrations. The spectral resolution of approximately $0.0176 \mu \mathrm{m}$ or $2.12 \mathrm{~cm}^{-1}$ results in a total of 93 spectral measurements per observation. In Fig. 1 the black line shows an example of HyTES-measured radiances. There is strong interference in this region from water vapor $\left(\mathrm{H}_{2} \mathrm{O}\right)$ and nitrous oxide $\left(\mathrm{N}_{2} \mathrm{O}\right)$, some interference by ozone $\left(\mathrm{O}_{3}\right)$, and weak interference from carbon dioxide. Thus, we simultaneously retrieve $\mathrm{H}_{2} \mathrm{O}$ and $\mathrm{N}_{2} \mathrm{O}$ with $\mathrm{CH}_{4}$ while keeping constant a priori profiles for the other minor gases in the forward model. Atmospheric temperature, surface temperature, and emissivity also affect the observed radiance and are therefore simultaneously retrieved with these trace gases as discussed in Worden et al. (2004).

\subsection{Forward model and a priori vectors}

To simulate radiances observed by the HyTES airborne sensor, the radiative transfer model is driven by a realistic temperature, surface temperature, atmospheric trace gas concentrations, cloud, and emissivity (Bowman et al., 2006). The forward model is based on the Line-By-Line Radiative Transfer Model (LBLRTM) (e.g., Clough et al. 2006; Worden et al., 2006; Alvarado et al., 2012). The a priori surface temperature, atmospheric temperature, and water vapor profiles are taken from the National Centers for Environmental Prediction/National Center for Atmospheric Research (NCEP/NCAR) Reanalysis dataset for the appropriate time and location (Kalnay et al., 1996).

Simulated high-resolution forward model radiances are convolved with the HyTES instrument line shape (ILS) function and sampled to the center wavenumber of each HyTES measured frequency. For example, Fig. 1 shows a comparison between a HyTES radiance measurement and the forward model radiance based on the a priori atmospheric profile. Differences between the measurement and model reflect differences in the actual and the a priori temperature, $\mathrm{H}_{2} \mathrm{O}$, $\mathrm{CH}_{4}$, and surface emissivity. Surface temperature and emissivity a priori information is derived by atmospherically cor- 

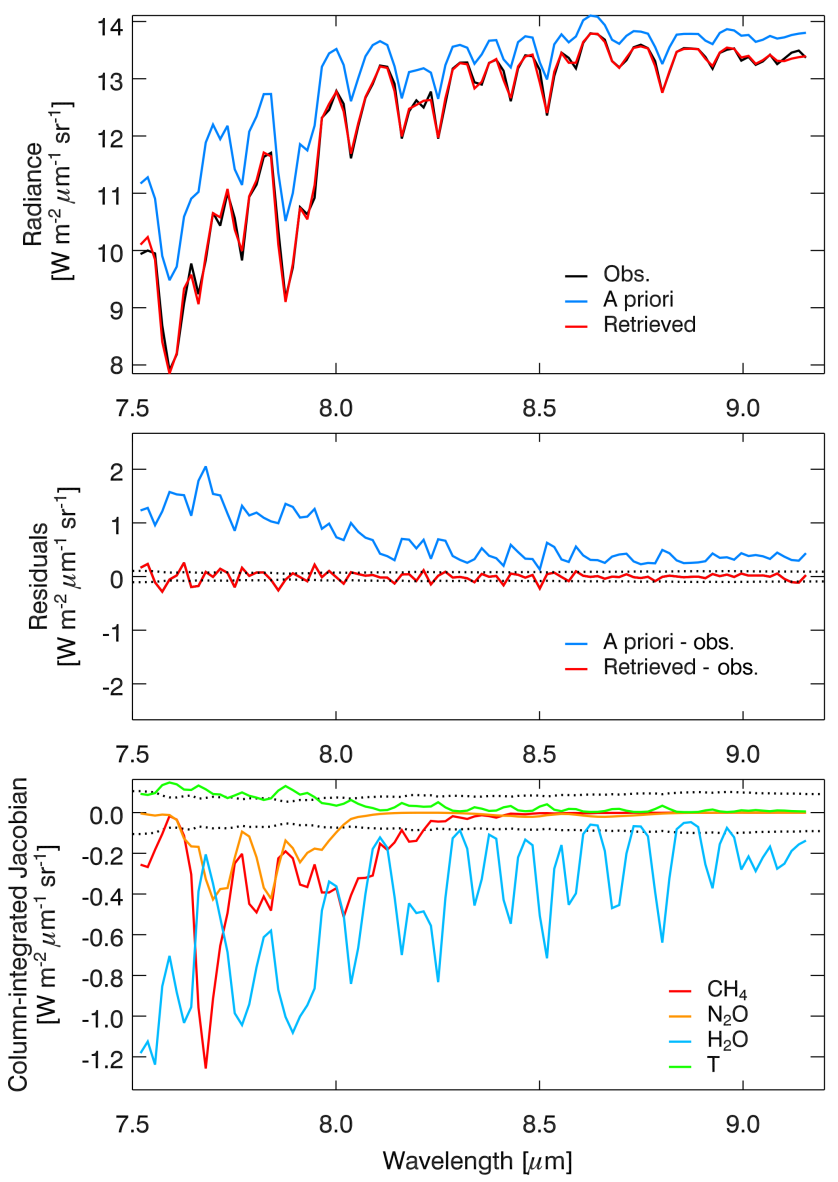

Figure 1. The spectral window for $\mathrm{CH}_{4}$ retrievals. Top: HyTESmeasured radiances (black) and two model-calculated radiances from a priori (blue) and retrieved states (red). Middle: residuals to the observations. Bottom: column-integrated Jacobians (sensitivity of radiance to $\mathrm{CH}_{4}$ and key interfering parameters). Noise levels are plotted by black dotted lines in both middle and bottom plots.

recting the HyTES radiance data using an in-scene atmospheric correction (ISAC) approach (Young et al., 2002). The advantage of the ISAC method is that atmospheric correction is accomplished using the hyperspectral data itself without the need for external atmospheric profiles. In addition, the issue of spectral band misregistrations between HyTES data and MODTRAN is eliminated by using the ISAC method instead of MOTRAN (Hulley et al., 2016). The temperatureemissivity separation algorithm (Gillespie et al., 1998) is then applied to the atmospherically corrected radiances to produce a surface temperature and spectral emissivity for the HyTES bands. This approach is currently being used to produce the HyTES Level-2 products available for ordering at http://hytes.jpl.nasa.gov/order.

\subsection{Retrieval methodology}

The observed spectral radiances $\boldsymbol{y}$ (function of wavenumber) by HyTES can be expressed as a sum of the model radiances $f(\boldsymbol{x})$, where $\boldsymbol{x}$ is a column state vector containing the quantities of interest (e.g., $\mathrm{CH}_{4}$ abundance), and spectral noise vector $\boldsymbol{n}$ :

$\boldsymbol{y}=f(\boldsymbol{x})+\boldsymbol{n}$.

The retrieval algorithm uses an optimal estimation approach (Rodgers, 2000; Bowman et al., 2006). Based on this approach, the estimate can be related to the "true state" (in this case the true distribution of $\mathrm{CH}_{4}$, temperature, $\mathrm{H}_{2} \mathrm{O}$, etc.) in the form of the following equation:

$\hat{x}=\boldsymbol{x}_{a}+\mathbf{A}\left(\boldsymbol{x}_{a}-\boldsymbol{x}\right)+\mathbf{G n}$,

where $\hat{x}, \boldsymbol{x}_{a}$ and $\boldsymbol{x}$ are the retrieved, a priori, and true state vectors respectively. The state vectors for trace gases, such as $\mathrm{H}_{2} \mathrm{O}, \mathrm{CH}_{4}$, and $\mathrm{N}_{2} \mathrm{O}$, are expressed in natural logarithm of volume mixing ratio (vmr). Atmospheric temperature, surface temperature, and surface emissivity are all retrieved linearly. In the model, there are three atmospheric layers (or four atmospheric levels) below the aircraft (which is at $\sim 1.2 \mathrm{~km}$ ) (see Fig. 3). We simultaneously estimate all of these parameters; therefore the state vector is given by a combination of these parameters:

$$
x=\left\{\begin{array}{l}
\ln q_{1}\left(\mathrm{CH}_{4}\right) \\
\ln q_{2}\left(\mathrm{CH}_{4}\right) \\
\ln q_{3}\left(\mathrm{CH}_{4}\right) \\
\ln q_{1}\left(\mathrm{H}_{2} \mathrm{O}\right) \\
\ln q_{2}\left(\mathrm{H}_{2} \mathrm{O}\right) \\
\ln q_{3}\left(\mathrm{H}_{2} \mathrm{O}\right) \\
\ln q_{1}\left(\mathrm{~N}_{2} \mathrm{O}\right) \\
\ln q_{2}\left(\mathrm{~N}_{2} \mathrm{O}\right) \\
\ln q_{3}\left(\mathrm{~N}_{2} \mathrm{O}\right) \\
T_{1} \\
T_{2} \\
T_{3} \\
T_{\text {surface }} \\
\varepsilon_{1} \\
\vdots \\
\varepsilon_{93}
\end{array}\right\},
$$

where the symbol $q_{i}(s)$ refers to the vmr of species $s$ at the $i$ th level. $T_{i}$ is the atmospheric temperature, and $\varepsilon_{j}$ is the surface emissivity at the $j$ th wavenumber. The signal-to-noise ratio for HyTES measurements varies with frequency in the window region for $\mathrm{CH}_{4}$ retrieval, ranging between 100 and $180 . \mathbf{G}=\frac{\partial x}{\partial \boldsymbol{y}}$ is the gain matrix, mapping from radiance space into profile space. The averaging kernel, $\mathbf{A}$, describes the sensitivity of the retrieved state to the true state:

$\mathbf{A}=\frac{\partial \hat{x}}{\partial \boldsymbol{x}}=\mathbf{H} \mathbf{K}^{\mathrm{T}} \mathbf{S}_{n}^{-1} \mathbf{K}=\mathbf{G K}$,

where $\mathbf{K}=\frac{\partial \boldsymbol{y}}{\partial \boldsymbol{x}}$, is the Jacobian, the sensitivity of the forward model radiances to the state vector. $\mathbf{H}$ is the Hessian matrix, 
which also represents the covariance matrix for the a posteriori state:

$\mathbf{H}=\left(\mathbf{K}^{T} \mathbf{S}_{n}^{-1} \mathbf{K}+\mathbf{S}_{a}^{-1}\right)^{-1}$.

$\mathbf{S}_{n}$ is the covariance matrix of the spectral noise, where the diagonal is the square of spectral uncertainty, calculated using the noise-equivalent temperature difference (NeDT) for the HYTES sensor. We assume that the noise correlations among the spectral channels (i.e., off-diagonal values of $\mathbf{S}_{n}$ ) are simply zero because such correlations are usually difficult to quantify while they do not make a significant impact on the retrieval. $\mathbf{S}_{a}$ is the covariance matrix for the a priori state, determined from observations and reanalysis. For instance, the diagonal of the "block" covariance matrix for $\mathrm{CH}_{4}$ is $32 \%$ squared at all levels at all levels, and its off-diagonal values are empirical correlations between the model levels (Bowman et al., 2006).

\subsection{Error analysis}

The error budget from a single retrieval can be characterized with the knowledge of the uncertainties of the a priori state and the measurement noise (Kuai et al., 2014). The error of the retrieved state is its difference from the true state:

$\delta \boldsymbol{x}=\hat{x}-\boldsymbol{x}=(\mathbf{I}-\mathbf{A})\left(\boldsymbol{x}_{a}-\boldsymbol{x}\right)+\mathbf{G} \boldsymbol{n}$,

where $\mathbf{I}$ is an identity matrix. The first term on the right-hand side of this equation is the smoothing error, including the components of systematic errors by $\mathrm{H}_{2} \mathrm{O}, \mathrm{N}_{2} \mathrm{O}$, temperature, emissivity, and so on. The second term represents the measurement error.

The total error covariance matrix after retrieval is

$\hat{\mathbf{S}}=(\mathbf{I}-\mathbf{A}) \mathbf{S}_{a}(\mathbf{I}-\mathbf{A})^{T}+\mathbf{G} \mathbf{S}_{n} \mathbf{G}^{T}$.

Since we are most interested in the error for the target gas $\left(\mathrm{CH}_{4}\right)$, the submatrix of the total error covariance matrix for $\mathrm{CH}_{4}$ can be rewritten, by separating covariance for a crossstate error from the covariance for the smoothing error (Worden et al., 2004), as

$\hat{\mathbf{S}}_{u u}=\left(\mathbf{I}-\mathbf{A}_{u u}\right) \mathbf{S}_{a}^{u u}\left(\mathbf{I}-\mathbf{A}_{u u}\right)^{T}+\mathbf{A}_{u v} \mathbf{S}_{a}^{u v}\left(\mathbf{A}_{u v}\right)^{T}+\mathbf{G S}_{n} \mathbf{G}^{T}$,

where the subscript $u$ refers to the state vector for the target gas, and $v$ refers to simultaneously retrieved parameters other than $\mathrm{CH}_{4}$. Therefore, $\mathbf{A}_{u u}$ represents the submatrix of $\mathbf{A}$ that is associated with the state vector for target gas $\left(\mathrm{CH}_{4}\right)$. The same applies to $\mathbf{S}_{a}^{u u}$ and $\mathbf{S}_{a}^{v v}$. $\mathbf{A}_{u v}$ refers to the submatrix of A that relates the sensitivity of the vector $\boldsymbol{u}$ to the vector of $\boldsymbol{v}$. With this equation, we can establish the contribution of each error term to the total error.
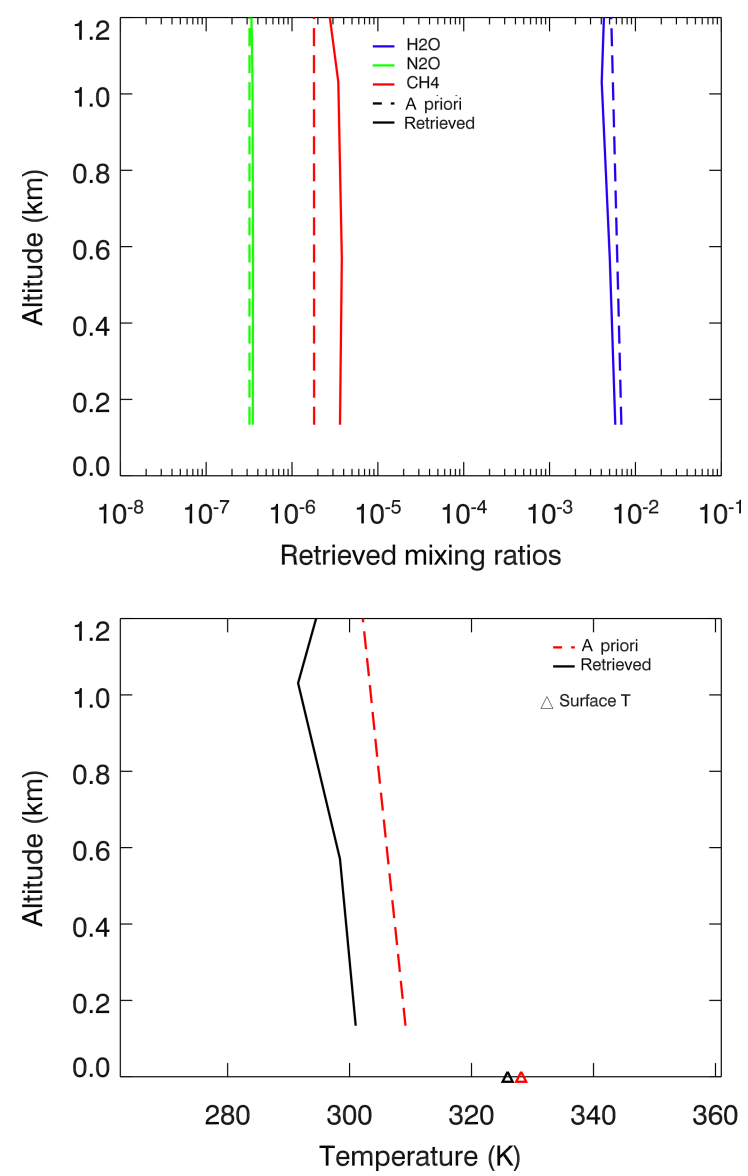

Figure 2. A priori (dash or red) and retrieved (solid or black) atmospheric states $\left(\mathrm{H}_{2} \mathrm{O}, \mathrm{N}_{2} \mathrm{O}, \mathrm{CH}_{4}\right.$, temperature, and surface temperature).

\section{Retrieval results and error budget}

Figure 1 shows an example of the retrieved radiances (red) and observed radiances (black), and radiances based on the a priori profiles (blue). The bottom plot shows the residuals between the retrieved and observed radiances. Figure 2 compares the retrieved profiles of $\mathrm{H}_{2} \mathrm{O}, \mathrm{CH}_{4}, \mathrm{~N}_{2} \mathrm{O}$, atmospheric temperature and surface temperature with their a priori values.

We constructed a "constraint" matrix for $\mathrm{CH}_{4}$ to regularize the $\mathrm{CH}_{4}$ retrieval (e.g., Bowman et al., 2006). This covariance has diagonal values of 0.32 (or $32 \%$ ) squared and offdiagonal values of the empirical correlations between levels. This covariance results in a degrees-of-freedom for signal (DOFS) of approximately 1 (for the retrieval shown in Fig. 3, we obtain 0.7). With this DOFS, we expect to observe variations that are larger than the calculated a posterior uncertainties that are partly based on the a priori covariance. Note that the detection of plumes by HyTES depends on the vertical distribution of the plume. For example, the averaging kernel shown in Fig. 3 peaks at approximately $0.6 \mathrm{~km}$ above 

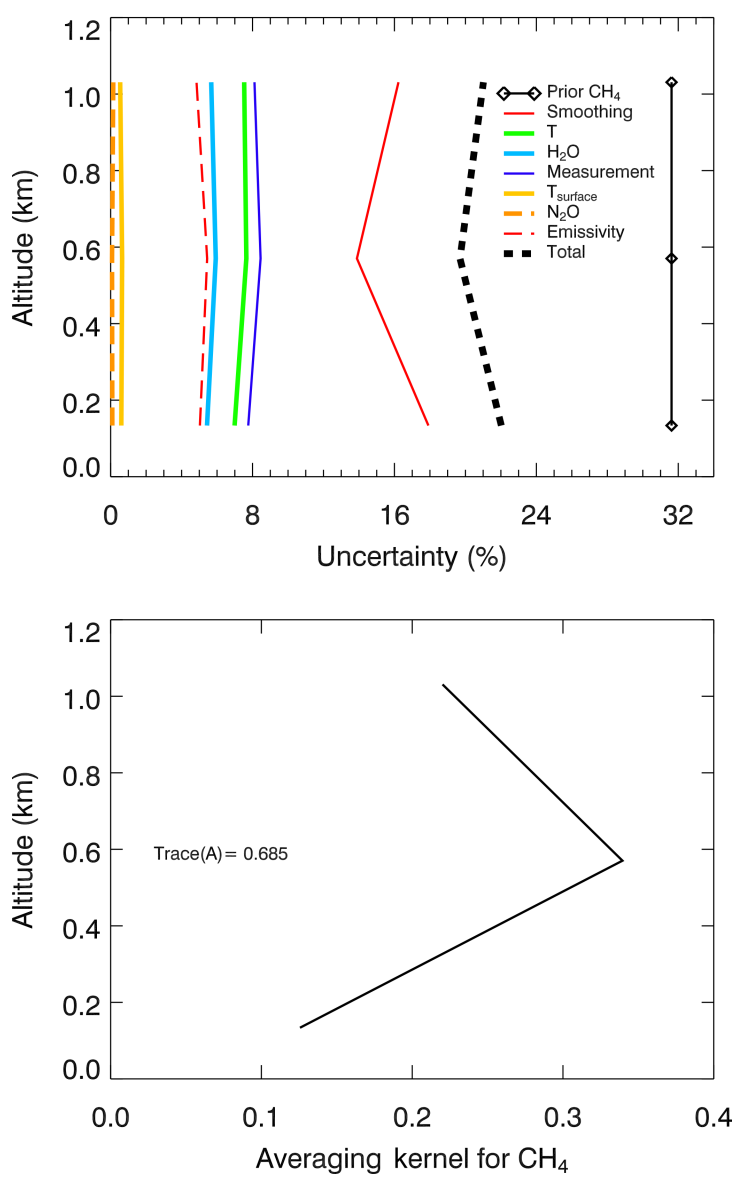

Figure 3. Error budget of the total error in retrieved $\mathrm{CH}_{4}$. The uncertainties of the a priori $\mathrm{CH}_{4}$ (about $32 \%$ ) drop to $20 \%$, the total error after the retrieval.

the surface, to which HyTES measurement is most sensitive. If plume concentrations are all below HyTES $0.6 \mathrm{~km}$, (e.g., when the boundary layer height is below $0.6 \mathrm{~km}$ ), the plume will be trapped primarily near the surface (where the averaging kernel is approximately 0.15 ) and it will be more challenging to detect the $\mathrm{CH}_{4}$ enhancement with these retrievals. In addition, to avoid the effects of boundary layer temperature inversion, the HyTES measurements are taken between noon and early afternoon.

The a posteriori uncertainty for the observed $\mathrm{CH}_{4}$ column (or average of the observed $\mathrm{CH}_{4}$ for the three retrieved atmospheric levels) is approximately $20 \%$, for example $0.4 \mathrm{ppm}$ for a background value of $2 \mathrm{ppm}$ (see Fig. 3). Dominant sources of the total error are the smoothing error, measurement error (noise), atmospheric temperature error, $\mathrm{H}_{2} \mathrm{O}$ error, and emissivity error. The contributions of surface temperature and $\mathrm{N}_{2} \mathrm{O}$ error to the total error are quite small.

In order to use these $\mathrm{CH}_{4}$ concentration estimates for quantifying emissions, we need to compute the total enhancement of the plume with respect to the local background, similar to the mass balance approach used by Tratt et al. (2014). The dominant error component for the precision is due to the measurement noise $(8 \%)$, which is usually random and can be greatly reduced by averaging. However, the systematic error due to radiative interferences is approximately $7 \%$, and this error will directly propagate into any corresponding emissions estimates.

\section{Mapping a methane plume from HyTES data}

We ran the $\mathrm{CH}_{4}$ retrievals of HyTES observations acquired from one flight line collected over one of many active plumes, west of the KROF, on 5 February 2015. Majority of the detected point sources originated from storage tanks (detected by cluster matched filter; Hulley, et al., 2016).

An image of 1000 by 512 pixels is originally taken, covering approximately $2 \mathrm{~km}^{2}$ area centered about $35^{\circ}$ latitude and $119^{\circ}$ longitude. The radiance measurements are resampled every $3 \times 3$ pixels to reduce the measurement noise and reduce computational time. Therefore, the spatial resolution of single target retrieval is now $6 \times 6 \mathrm{~m}^{2}$ after the resampling.

A map of the retrieved $\mathrm{CH}_{4}$ concentration in the boundary layer is shown along with an image of $\mathrm{CH}_{4}$ concentration variability calculated using the CMF method (Hulley et al., 2016) in Fig. 4. The maps of both quantitative retrieval and CMF are the cut-off area over the plume from a whole line. The concentration in each pixel is the vertical average of the retrieved $\mathrm{CH}_{4}$ profile. In the CMF image, the green pixels suggest the detection of plume with higher concentrations of $\mathrm{CH}_{4}$ above the background value. Both images consistently show a large-scale and well-developed $\mathrm{CH}_{4}$ plume with maximum enhancements relative to background right above several storage tanks at the surface. Elevated $\mathrm{CH}_{4}$ concentrations are observed in the plume in excess of $3 \pm 0.6 \mathrm{ppm}$ within box $\mathrm{b}$ in Fig. 4, with a maximum enhancement of $6 \pm 1.2 \mathrm{ppm}$ and decreasing towards the downwind side and spread over a larger area (Fig. 4 box c and d). A wind of the $10 \mathrm{~min}$ averaged speed is $1.3 \mathrm{~m} \mathrm{~s}^{-1}$ with a direction of $227^{\circ}$ to the north, shown in the CMF image. Lower concentrations of about $1.8 \mathrm{ppm}$ are observed for the rest of this scene, presenting a background region (such as box a). Some scattered, high-biased concentrations of approximately $2.3 \mathrm{ppm}$ are observed away from the plume or at the upwind side of the point source that are likely artifacts of spectral interference from temperature and $\mathrm{H}_{2} \mathrm{O}$ because they co-vary with their retrieved quantities and because they are within the calculated uncertainties. Note that the uncertainties are not necessarily a normal distribution as they also depend on variations in the interfering quantities such as air temperature and $\mathrm{H}_{2} \mathrm{O}$. Consequently, $\mathrm{CH}_{4}$ variations at these levels are very difficult to distinguish from the background variations given the estimated uncertainties of $\sim 20 \%$ (or $\sim 0.5 \mathrm{ppm}$ ).

We used a chi-square threshold, $\chi^{2} \leq 1.2$, as the primary quality control indicating a "good" retrieval, where $\chi^{2}$ is the root mean square of the ratio of spectral residuals to 

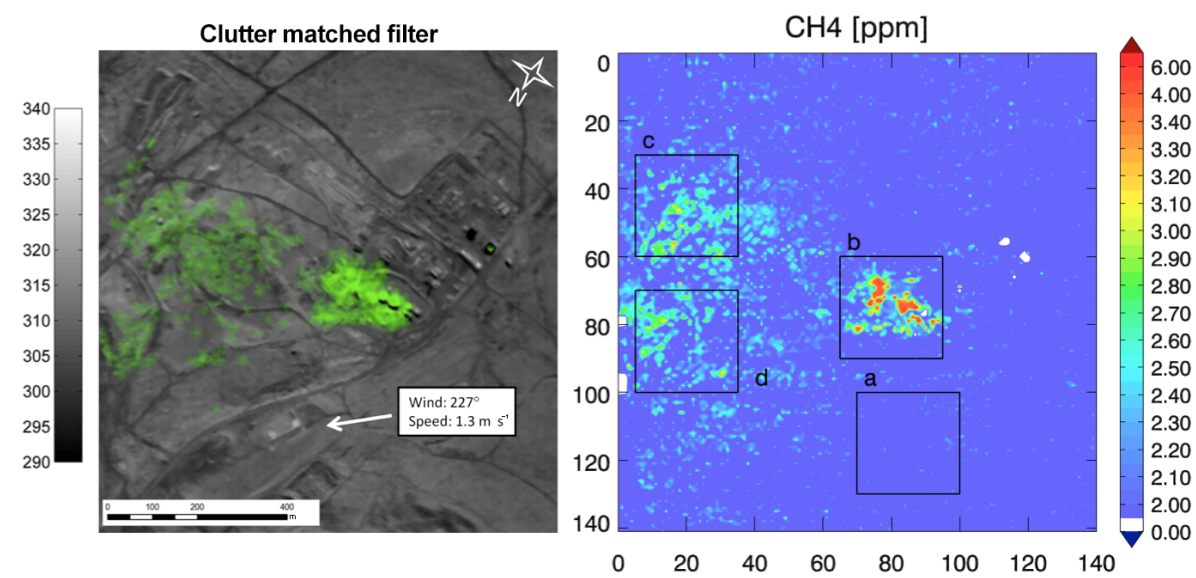

Figure 4. Left: HyTES-detected $\mathrm{CH}_{4}$ plumes (in green) from oil tanks on 5 February 2015 in Kern County, CA, and overlaid on the grayscale surface temperature image. Right: the $\mathrm{CH}_{4}$ concentration of the same region from the retrieval estimation. White pixels are bad data and are set to be zero. The arrow on the CMF image is showing a wind direction of $227^{\circ}$ to the north with a 10 min average speed of $1.3 \mathrm{~m} \mathrm{~s}{ }^{-1}$.

the measurement noise. White pixels are those bad retrievals $\left(\chi^{2}>1.2\right)$ that fail to pass the quality flag and are set to be $0 \mathrm{ppm}$. For example, two blocks on the upper right side away from the point source of unusually elevated $\mathrm{CH}_{4}$ are estimated for more than $7 \mathrm{ppm}$, which result from abnormal large negative thermal contrasts. However, the corresponding chisquare of more than 1.2 identified these pixels to be bad data. The identified plume for these pixels in CMF data is actually false positives.

Figure 5a show that the distributions for $\mathrm{CH}_{4}$ concentrations over the hotspot area (box b, c and d in Fig. 4) are distinguishable from the distributions of background areas (box a). The signal of those significant enhancements over the storage tanks is larger than the background uncertainties. The distribution for the plume in box b displays a nice long tail structure. Similar asymmetric distribution is found for box $\mathrm{c}$ and $\mathrm{d}$; outflows of the emission followed wind direction. For the background areas, the histogram in box a has more of a Gaussian distribution.

\section{Comparison of HyTES to airborne and ground-based in situ $\mathrm{CH}_{4}$}

A $\mathrm{CH}_{4}$ profile was measured in tandem with HyTES flights on 5 February by an instrumented aircraft used by the CARVE (Carbon in Arctic Reservoirs Vulnerability Experiment) project during its winter downtime (Miller and Dinardo, 2012). CARVE uses rapid response cavity ring down spectroscopy (G1401, Picarro Inc.) to measure $\mathrm{CH}_{4}$ (as well as $\mathrm{CO}_{2}$ and $\mathrm{CO}$ ) in flight, and records temperature, pressure, and location. CARVE data were collected by flying toward and away from the plume area within the boundary layer (between 963 and $979 \mathrm{hPa}$ ), and then spiraling up in a larger area to obtain the vertical profile in the free troposphere between 963 and $692 \mathrm{hPa}$. For the lower boundary layer (i.e., below
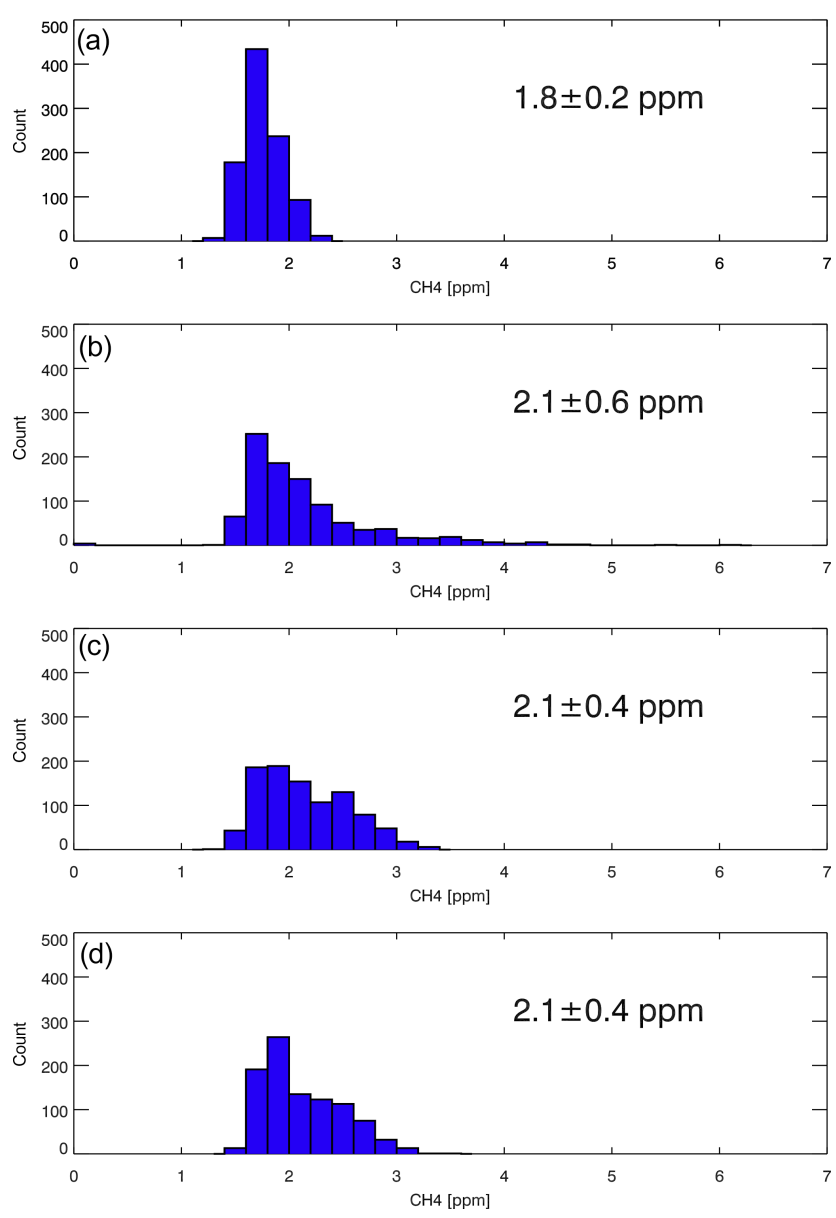

Figure 5. The distributions the $\mathrm{CH}_{4}$ concentrations in the area of four boxes defined in Fig. 4. (a) Background area; (b) the point source region; (c) and (d) are both downwind areas. 


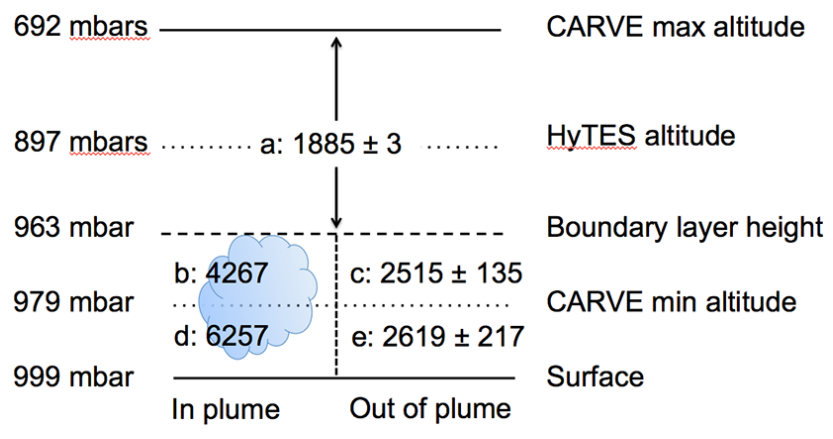

Figure 6. Partial column average (in ppb) to profile $\mathrm{CH}_{4}$ in the plume and background region with CARVE and vehicle data.

$979 \mathrm{hPa}$ ), surface $\mathrm{CH}_{4}$ observations were used from vehicle transects that intersected the plume. The vehicle observations were made by an on-board G2401 (Picarro, Inc.) that was calibrated against the G1401 on CARVE.

Within the boundary layer, we divided CARVE and onroad data into in-plume and out-of-plume measurements, giving us two profiles to represent the plume profile and background profile (Fig. 6). The two profiles, interpolated from three atmospheric levels (i.e., surface to $979 \mathrm{hPa}$ from on-road, 979 to $963 \mathrm{hPa}$ for airborne in boundary layer, and 963 to $897 \mathrm{hPa}$ for the free troposphere in the HyTES partial column), are then convolved with the HyTES averaging kernel and $\mathrm{CH}_{4}$ a priori constraint which represents the HyTES "instrument" function that accounts for the instrument characteristics and retrieval approach for HyTES $\mathrm{CH}_{4}$ estimates with the following equation:

$\hat{x}=\boldsymbol{x}_{a}-\mathbf{A}\left(\boldsymbol{x}-\boldsymbol{x}_{a}\right)$.

Table 1 summarizes the vertical average of $\mathrm{CH}_{4}$ below $1 \mathrm{~km}$ in both the background region and plume area by CARVE and HyTES. In the background region, the quantitative retrievals of HyTES data suggest the background value of the whole area is $1.80 \pm 0.20 \mathrm{ppm}$, consistent (within precision) with the in situ $\mathrm{CH}_{4}$ measurements convolved with the averaging kernel. The bias (= in situ $\mathrm{CH}_{4}$ with AK - HyTES in the background) of $0.22 \mathrm{ppm}$ to in situ data is consistent with the estimated systematic error of 6-7\% due to temperature or $\mathrm{H}_{2} \mathrm{O}$ bias or both (see Fig. 3). The precision of $0.20 \mathrm{ppm}$ is consistent with the estimated random error of $8 \%$ from measurement noise. In the plume area, the average of the plume pixels $(>2.2 \mathrm{ppm})$ in box b is $2.86 \mathrm{ppm}$, very close to the value of the plume measured in situ. The precision, however, is degraded to $0.62 \mathrm{ppm}$ due to the random erros in temperature and $\mathrm{H}_{2} \mathrm{O}$.

\section{Conclusions}

In this study, we estimated $\mathrm{CH}_{4}$ concentrations in one of many active plumes in the Kern River Oil Field using air-
Table 1. $\mathrm{CH}_{4}$ vertical average below HyTES flight height. In situ $\mathrm{CH}_{4}$ with $\mathrm{AK}$ is the in situ $\mathrm{CH}_{4}$ measurement convolved with the HyTES averaging kernel (AK).

\begin{tabular}{lrr}
\hline Unit (ppm) & Background & In plume \\
\hline In situ $\mathrm{CH}_{4}$ & 2.13 & 3.34 \\
In situ $\mathrm{CH}_{4}$ with AK & 2.02 & 2.84 \\
HyTES & $1.80 \pm 0.2$ & $2.86 \pm 0.62$ \\
\hline
\end{tabular}

borne thermal IR radiance measurements from HyTES flying at approximately $1 \mathrm{~km}$ a.g.l. The DOFS for a retrieval of $\mathrm{CH}_{4}$ concentration from HyTES measurements is close to 1. The single pixel uncertainties are about $20 \%$ of the estimated $\mathrm{CH}_{4}$ concentrations for an integrated column between the surface and aircraft. The primary sources of the uncertainties are found to be measurement noise, atmospheric temperature, surface emissivity, and $\mathrm{H}_{2} \mathrm{O}$. Minor errors are introduced by $\mathrm{N}_{2} \mathrm{O}$ and surface temperature.

Enhanced $\mathrm{CH}_{4}$ concentrations of approximately $3 \pm 0.6$ to $6 \pm 1.2 \mathrm{ppm}$ are observed above some storage tanks. This $\mathrm{CH}_{4}$ source is observed continuously releasing elevated $\mathrm{CH}_{4}$ during other HyTES flight lines on 8 and 9 February 2015, detected by CMF while has not been processed with quantitative retrieval yet. The background value around this region is approximately $1.8 \pm 0.2 \mathrm{ppm}$. This background value of $1.8 \pm 0.2 \mathrm{ppm}$ is consistent with aircraft measurements of background $\mathrm{CH}_{4}$ in the region of approximately $2 \mathrm{ppm}$ as the accuracy of the HyTES data is approximately $8 \%$ or $\sim 0.16 \mathrm{ppm}$.

A future study will apply this retrieval algorithm to a larger number of point sources and cross compare the HyTES quantitative retrievals with in situ measurements, such as road data or other airborne observations, such as CARVE and the Next Generation Airborne Visible Infrared Spectrometer (AVIRIS-NG) during a multi-aircraft, multi-platform campaign.

\section{Data availability}

The HyTES products can be downloaded at http://hytes.jpl. nasa.gov/order. The data used in this paper are archived at Jet Propulsion Laboratory (JPL) and are available from the authors upon request (lkuai@g.ucla.edu).

Acknowledgements. We would like to thank all other HyTES team members and the pilots for making the measurements and calibrating the data. This research was carried out at the Jet Propulsion Laboratory, California Institute of Technology, under a contract with the National Aeronautics and Space Administration. K.-F. Li was supported by NASA grant NNX14AR40G to the University of Washington. 
Edited by: F. Prata

Reviewed by: F. Prata and one anonymous referee

\section{References}

Alvarado, M. J., Payne, V. H., Mlawer, E. J., Uymin, G., Shephard, M. W., Cady-Pereira, K. E., Delamere, J. S., and Moncet, J.L.: Performance of the Line-By-Line Radiative Transfer Model (LBLRTM) for temperature, water vapor, and trace gas retrievals: recent updates evaluated with IASI case studies, Atmos. Chem. Phys., 13, 6687-6711, doi:10.5194/acp-13-6687-2013, 2013.

Bowman, K. W., Rodgers, C. D., Kulawik, S., Worden, J., Sarkissian, E., Osterman, G., Steck, T., Lou, M., Eldering, A., Shephard, M., Worder, H., Lampel, M., Clough, S., Brown, P., Rinsland, C., Gunson, M., and Beer, R.: Tropospheric emission spectrometer: retrieval method and error analysis, IEEE T. Geosci. Remote, 44, 1297-1307, 2006.

Caulton, D. R., Shepson, P. B., Santoro, R. L., Sparks, J. P., Howarth, R. W., Ingraffea, A. R., Cambaliza, M. O., Sweeney, C., Karion, A., and Davis, K. J.: Toward a better understanding and quantification of methane emissions from shale gas development, P. Natl. Acad. Sci. USA, 111, 6237-6242, 2014.

Clough, S. A., Shephard, M. W., Worden, J., Brown, P. D., Worden, H. M., Luo, M., Rodgers, C. D., Rinsland, C. P., Goldman, A., and Brown, L.: Forward model and Jacobians for tropospheric emission spectrometer retrievals, IEEE T. Geosci. Remote, 44, 1308-1323, 2006.

Etheridge, D. M., Steele, L. P., Francey, R. J., and Langenfelds, R. L.: Atmospheric methane between $1000 \mathrm{AD}$ and present: Evidence of anthropogenic emissions and climatic variability, J. Geophys. Res., 103, 15979-15993, doi:10.1029/98JD00923, 1998.

Frankenberg, C., Aben, I, Bergamaschi, P., Dlugokencky, E. J., van Hees, R., Houweling, S., van der Meer, P., Snel, R., and Tol, P.: Global column-averaged methane mixing ratios from 2003 to 2009 as derived from SCIAMACHY: Trends and variability, J. Geophys. Res., 116, D04302, doi:10.1029/2010JD014849, 2011.

Funk, C. C., Theiler, J., Roberts, D. A., and Borel, C. C.: Clustering to improve matched filter detection of weak gas plumes in hyperspectral thermal imagery, IEEE T. Geosci. Remote, 39, 1410-1420, 2001.

Gerilowski, K., Krings, T., Hartmann, J., Buchwitz, M., Sachs, T., Erzinger, J., Burrows, J. P., and Bovensmann, H.: Atmospheric remote sensing constraints on direct sea-air methane flux from the 22/4b north sea massive blowout bubble plume, Mar. Petrol. Geol., 68, 824-835, 2015.

Gillespie, A., Rokugawa, S., Matsunaga, T., Cothern, J. S., Hook, S., and Kahle, A. B.: A temperature and emissivity separation algorithm for Advanced Spaceborne Thermal Emission and Reflection Radiometer (ASTER) images, IEEE T. Geosci. Remote, 36, 1113-1126, doi:10.1109/36.700995, 1998.

Hook, S. J., Johnson W. R., and Abrams, M. J.: NASA's Hyperspectral Thermal Emission Spectrometer (HyTES), In Thermal Infrared Remote Sensing, Springer, 527 pp., 2013.

Hook, S. J., Hulley, G. E., Johnson, W. R., Eng, B., Mihaly, J., Chazanoff S., Vance N., Staniszewski Z., Rivera G., Holmes K. T., and Guillevic P.: The Hyperspectral Thermal Emission Spectrometer
(HyTES) - A New Hyperspectral Thermal Infrared Airborne Imager for Earth Science, Remote Sens. Environ., submitted, 2016.

Hsu, Y. K., VanCuren, T., Park, S., Jakober, C., Herner, J., FitzGibbon, M., Blake, D. R., and Parrish, D. D.: Methane emissions inventory verification in southern California, Atmos. Environ., 44, 1-7, doi:10.1016/j.atmosenv.2009.10.002, 2010.

Hulley, G. C., Duren, R. M., Hopkins, F. M., Hook, S. J., Vance, N., Guillevic, P., Johnson, W. R., Eng, B. T., Mihaly, J. M., Jovanovic, V. M., Chazanoff, S. L., Staniszewski, Z. K., Kuai, L., Worden, J., Frankenberg, C., Rivera, G., Aubrey, A. D., Miller, C. E., Malakar, N. K., Sánchez Tomás, J. M., and Holmes, K. T.: High spatial resolution imaging of methane and other trace gases with the airborne Hyperspectral Thermal Emission Spectrometer (HyTES), Atmos. Meas. Tech., 9, 2393-2408, doi:10.5194/amt9-2393-2016, 2016.

Jeong, S., Hsu, Y. K., Andrews, A. E., Bianco, L., Vaca, P., Wilczak, J. M., and Fischer, M. L.: A multitower measurement network estimate of California's methane emissions, J. Geophys. Res., 118, 11339-11351, doi:10.1002/jgrd.50854, 2013.

Kalnay, E., Kanamitsu, M., Kistler, R., Collins, W., Deaven, D., Gandin, L., Iredell, M., Saha, S., White, G., Woollen, J., Zhu, Y., Chelliah, M., Ebisuzaki, W., Higgins, W., Janowiak, J., Mo, K. C., Ropelewski, C., Wang, J., Leetmaa, A., Reynolds, R., Jenne, R., and Joseph, D.: The NCEP/NCAR 40-year reanalysis project, B. Am. Meteorol. Soc., 77, 437-471, doi:10.1175/15200477(1996)077<0437:TNYRP>2.0.CO;2, 1996.

Kirschke, S., Bousquet, P., Ciais, P., Saunois, M., Canadell, J. G., Dlugokencky, E. J., Bergamaschi, P., Bergmann, D., Blake, D. R., and Bruhwiler, L.: Three decades of global methane sources and sinks, Nature Geosci., 6, 813-823, 2013.

Kort, E. A., Frankenberg, C., Costigan, K. R., Lindenmaier, R., Dubey, M. K., and Wunch, D.: Four corners: The largest US methane anomaly viewed from space, Geophys. Res. Lett., 41, 6898-6903, 2014.

Krings, T., Gerilowski, K., Buchwitz, M., Hartmann, J., Sachs, T., Erzinger, J., Burrows, J. P., and Bovensmann, H.: Quantification of methane emission rates from coal mine ventilation shafts using airborne remote sensing data, Atmos. Meas. Tech., 6, 151-166, doi:10.5194/amt-6-151-2013, 2013.

Kuai, L., Worden, J., Kulawik, S. S., Montzka, S. A., and Liu, J.: Characterization of Aura TES carbonyl sulfide retrievals over ocean, Atmos. Meas. Tech., 7, 163-172, doi:10.5194/amt-7-1632014, 2014.

Lelieveld, J., Crutzen, P. J., and Dentener, F. J.: Changing concentration, lifetime and climate forcing of atmospheric methane, Tellus B, 50, 128-150, doi:10.1034/j.1600-0889.1998.t01-1-00002.x, 1998.

McKain, K., Down, A., Raciti, S. M., Budney, J., Hutyra, L. R., Floerchinger, C., Herndon, S. C., Nehrkorn, T., Zahniser, M. S., Jackson, R. B., Phillips, N., and Wofsy, S. C.: Methane emissions from natural gas infrastructure and use in the urban region of Boston, Massachusetts, P. Natl. Acad. Sci. USA, 112, 19411946, doi:10.1073/pnas.1416261112, 2015.

Miller, C. E. and Dinardo, S. J.: CARVE: The Carbon in Arctic Reservoirs Vulnerability Experiment, 2012 IEEE Aerospace Conference, 1-17, doi:10.1109/AERO.2012.6187026, 2012.

NOAA: GMD Measurement Locations, National Oceanic \& Atmospheric Adminstration (NOAA), Earth System Research Laboratory, Global Measurement Division, 2013. 
Peischl, J., Ryerson, T. B., Brioude, J., Aikin, K. C., Andrews, A. E., Atlas, E., Blake, D., Daube, B. C., de Gouw, J. A., Dlugokencky, E., Frost, G. J., Gentner, D. R., Gilman, J. B., Goldstein, A. H., Harley, R. A., Holloway, J. S., Kofler, J., Kuster, W. C., Lang, P. M., Novelli, P. C., Santoni, G. W., Trainer, M., Wofsy, S. C., and Parrish, D. D.: Quantifying sources of methane using light alkanes in the Los Angeles basin, California, J. Geophys. Res.Atmos., 118, 4974-4990, doi:10.1002/jgrd.50413, 2013.

Ramaswamy: The Third Assessment Report of the Intergovernmental Panel on Climate Change, edited by: Houghton, J. T., Ding, Y., Griggs, D. J., Noguer, M., van der Linden, P. J., Dai, X., Maskell, K. and Johnson, C. A., Cambridge Univ. Press, 349-416, 2001.

Rodgers, C. D.: Inverse Methods for Atmospheric Sounding: Theory and Practice, World Scientific, London, 256 pp., 2000.

Solomon, S., Qin, D., Manning, M., Chen, Z., Marquis, M., Averyt, K. B., Tignor, M., and Miller, H. L. (Eds.): IPCC: Climate Change 2007: The Physical Science Basis. Contribution of Working Group I to the Fourth Assessment Report of the Intergrovernmental Panel on Climate Change, Intergovernmental Panel on Climate Change (IPCC), Cambridge Univ. Press, UK and New York, USA, 996, 2007.

Tratt, D. M., Buckland, K. N., Hall, J. L., Johnson, P. D., Keim, E. R., Leifer, I., Westberg, K., and Young, S. J.: Airborne visualization and quantification of discrete methane sources in the environment, Remote Sens. Environ., 154, 74-88, 2014.

Wennberg, P. O., Mui, W., Wunch, D., Kort, E. A., Blake, D. R., Atlas, E. L., Santoni, G. W., Wofsy, S. C., Diskin, G. S., Jeong, S., and Fischer, M. L.: On the Sources of Methane to the Los Angeles Atmosphere, Environ. Sci. Technol., 46, 9282-9289, doi:10.1021/es301138y, 2012.
Wong, K. W., Fu, D., Pongetti, T. J., Newman, S., Kort, E. A., Duren, R., Hsu, Y.-K., Miller, C. E., Yung, Y. L., and Sander, S. P.: Mapping $\mathrm{CH}_{4}: \mathrm{CO}_{2}$ ratios in Los Angeles with CLARSFTS from Mount Wilson, California, Atmos. Chem. Phys., 15, 241-252, doi:10.5194/acp-15-241-2015, 2015.

Worden, J., Kulawik, S. S., Shephard, M., Clough, S. A., Worden, H., Bowman, K., and Goldman, A.: Predicted errors of tropospheric emission spectrometer nadir retrievals from spectral window selection, J. Geophys. Res., 109, D09308, doi:10.1029/2004JD004522, 2004.

Worden, J., Bowman, K., Noone, D., Beer, R., Clough, S., Eldering, A., Fisher, B., Goldman, A., Gunson, M., Herman, R., Kulawik, S. S., Lampel, M., Luo, M., Osterman, G., Rinsland, C., Rodgers, C., Sander, S., Shephard, M., and Worden, H.: Tropospheric Emission Spectrometer observations of the tropospheric $\mathrm{HDO} / \mathrm{H}_{2} \mathrm{O}$ ratio: Estimation approach and characterization, J. Geophys. Res., 111, D16309, doi:10.1029/2005JD006606, 2006.

Worden, J., Kulawik, S., Frankenberg, C., Payne, V., Bowman, K. Cady-Peirara, K., Wecht, K., Lee, J.-E., and Noone, D.: Profiles of $\mathrm{CH}_{4}, \mathrm{HDO}, \mathrm{H}_{2} \mathrm{O}$, and $\mathrm{N}_{2} \mathrm{O}$ with improved lower tropospheric vertical resolution from Aura TES radiances, Atmos. Meas. Tech., 5, 397-411, doi:10.5194/amt-5-397-2012, 2012.

Wunch, D., Wennberg, P. O., Toon, G. C., Keppel-Aleks, G., and Yavin, Y. G.: Emissions of greenhouse gases from a North American megacity, Geophys. Res. Lett., 36, L15810, doi:10.1029/2009GL039825, 2009.

Young, S. J., Johnson, B. R., and Hackwell, J. A.: An in-scene method for atmospheric compensation of thermal hyperspectral data, J. Geophys. Res., 107, 4774, doi:10.1029/2001JD001266, 2002. 